\title{
EVALUACIÓN DE LÍNEAS DE FRíJOL (Phaseolus vulgaris L.) DE RETROCRUCE AVANZADO ENTRE UNA ACCESIÓN SILVESTRE Y RADICAL CERINZA
}

\section{EVALUATION OF BEAN (Phaseolus vulgaris L.) LINES RESULT OF AN ADVANCED BACKCROSS BETWEEN A WILD ACCESSION AND RADICAL CERINZA}

\author{
Hernando Delgado ${ }^{1}$, Elberth Hernando Pinzón ${ }^{2}$, Mathew Blair ${ }^{3}$, Paulo César Izquierdo ${ }^{4}$
}

\begin{abstract}
${ }^{1}$ I. Agr. M.Sc. Fitotecnia: Genética y Fitomejoramiento. Profesor Asistente. Grupo Manejo Biológico de Cultivos. GMBC. Facultad de Ciencias Agropecuarias, Universidad Pedagógica y Tecnológica de Colombia. UPTC. Av. Central del Norte. Tunja, Colombia. e-mail: hdelgadoster@gmail.com (Entidad actual: Universidad de los Llanos. Km 12 Vía Puerto López. Vereda Barcelona. Villavicencio, Colombia); ${ }^{2}$ I. Agr. Facultad de Ciencias Agropecuarias, Universidad Pedagógica y Tecnológica de Colombia. UPTC. Av. Central del Norte. Tunja, Colombia. e-mail: Elberth02@gmail.com; ${ }^{3}$ Fitomejorador. Ph.D. Fríjol Andico. Centro Internacional de Agricultura Tropical. CIAT. Km 17 recta Cali-Palmira. Cali, Colombia. e-mail: mwbeans@gmail. com (Entidad actual: Universidad Nacional de Colombia. Sede Palmira); ${ }^{4}$ Biólogo. Investigador Visitante. Laboratorio de Caracterización de Germoplasma de Frijol. Centro Internacional de Agricultura Tropical, CIAT. Km 17 recta Cali-Palmira. Cali, Colombia. e-mail: pauloizquierdo@gmail.com (Entidad actual: CENICAÑA. Cali).
\end{abstract}

Rev. U.D.C.A Act. \& Div. Cient. 16(1): 79 - 86, 2013

\section{RESUMEN}

Con el objeto de seleccionar líneas parentales promisorias con adaptación a la zona, adecuado rendimiento y tipo de grano, se evaluaron 100 genotipos (95 líneas RC2 y 5 testigos) de fríjol arbustivo (Phaseolus vulgaris L.) en un diseño de látice 10 x 10, en la Granja Experimental Tunguavita en el municipio de Paipa, Boyacá. Las líneas RC2 provienen de retrocruce avanzado entre la población Radical Cerinza (padre recurrente) y la accesión silvestre G10022 (padre donante). Se registraron datos de vigor, días a floración y a madurez, rendimiento de grano y sus componentes: número de vainas por planta, número de granos por vaina y peso de 100 granos. El rendimiento final de grano presentó sus mayores coeficientes de correlación y significancia con los componentes número de vainas por planta y peso de 100 granos. Se identificaron varias líneas manifestando segregación transgresiva sobre el padre recurrente Radical Cerinza, en las variables número de vainas por planta, peso de 100 granos y rendimiento final, con siete líneas superiores significativamente en rendimiento y adecuado tipo de grano. La línea de mayor rendimiento con $3.894 \mathrm{~kg} \mathrm{ha}^{-1}$ superó al padre recurrente, en $1.811 \mathrm{~kg} \mathrm{ha}^{-1}$. Estos resultados indican que la metodología de retrocruces avanzados se está mostrando como eficiente para introgresar genes para alto rendimiento, desde accesiones silvestres hacia cultivares mejorados. Las líneas de mejor comportamiento deberán seguir siendo avanzadas con dicha metodología, para la búsqueda de progenitores donantes de genes para alto rendimiento, para la obtención de nuevas variedades mejoradas de fríjol arbustivo, para la zona fría del Departamento de Boyacá.

Palabras clave: Retrocruce avanzado, pre-mejoramiento, fríjol, rendimiento y componentes.

\section{SUMMARY}

In order to select potential parents with adaptation to the area, adequate yield and grain type, 100 genotypes (95 RC2 lines and 5 witnesses) of bush bean (Phaseolus vulgaris L.) were evaluated in a lattice design $10 \times 10$ at the Experimental Farm Tunguavita, Paipa-Boyaca. The RC2 lines were obtained from an advanced backcross between Radical Cerinza population (recurrent parent) and a wild accession G 10022 (donor parent). Vigor, days to flowering and maturity, grain yield and its components: number of pods per plant, number of grains per pod and weight of 100 grains, were evaluated. The final grain yield showed its highest correlation coefficients and significance for the components number of pods per plant and weight of 100 grains. Several lines, expressing transgressive segregation of Radical Cerinza, the recurrent parent, in the variables number of pods per plant, weight of 
100 grains and final yield, with seven significantly superior lines in yield and appropriate grain type were identified. The line of maximum yield with $3.894 \mathrm{~kg} \mathrm{ha}^{-1}$ exceeded the recurrent parent in $1.811 \mathrm{~kg} \mathrm{ha}^{-1}$. These results indicate that the advanced backcross method is proving to be efficient for high yield genes, introgressed from wild accessions to improved cultivars. The lines with best yields should furthermore be advanced with this methodology, in the search of donor parents of high yield genes to obtain new bush bean improved varieties, for cold climate of the Boyacá department.

Key words: Advanced backcross, pre-breeding, beans, yield and components.

\section{INTRODUCCIÓN}

El fríjol común (Phaseolus vulgaris L.) es la especie más importante para el consumo humano, entre las leguminosas de grano alimenticias. Tiene gran importancia en la dieta de la población colombiana, por su alto contenido proteico $\mathrm{y}$ de minerales esenciales, siendo un producto clave en la seguridad alimentaria. Hacen ventajoso su consumo, desde el punto de vista nutricional, su elevado contenido de lisina, fibra alimentaria y presencia de vitaminas del complejo B (Voysest, 2000; Arias et al. 2007). Su producción abarca áreas muy diversas, cultivándose prácticamente en todo el mundo. América Latina es el mayor productor y consumidor, con más del $45 \%$ de la producción mundial (CNPAF- EMBRAPA, 2003).

Colombia es uno de los principales productores de fríjol en la zona andina, con alrededor de 86.134 hectáreas, sembradas por año. Los departamentos de mayor producción son Antioquia, Huila, Santander, Nariño, Tolima y Boyacá (CCI \& MADR, 2009); debido a las bondades del clima y la lluvia, el rendimiento está entre los mayores en América Latina, con un promedio de $1.200 \mathrm{~kg} \mathrm{ha}^{-1}$. La variabilidad de ambientes, desde los 500 hasta los 2.800msnm, permite la producción de muchas variedades, entre las cuales, se destacan los cargamantos y bola rojas, para los volubles y los calima, nima y radicales, para los arbustivos (Arias et al. 2007).

Según la Encuesta Nacional Agropecuaria (CCI \& MADR, 2009), en el departamento de Boyacá se sembraron 7.266ha de fríjol, distribuidas en 26.492 unidades productoras, con una producción de $10.515 \mathrm{t}$ y un rendimiento promedio de $1,4 \mathrm{t} \mathrm{ha}^{-1}$.

Debido a que el fríjol es una especie autógama y su reproducción sexual es por autofecundación, cada genotipo tiende a aislarse de otro, restringiendo el libre intercambio de genes. Por esto, la base genética de los cultivares mejorados es en realidad muy estrecha (Adams, 1977; McClean et al. 1993; Voysest et al. 1994) y, únicamente, un cierto tipo de cultivares, genéticamente muy relacionados, predomina en cada zona. Así, se logra muy poca o ninguna ganancia genética, a través de cruzamientos entre cultivares de la misma clase comercial o acervos de fríjol, siendo el mayor limitante a la hora de mejorar el rendimiento (Singh et al. 1989). Además, el mejoramiento para alto rendimiento debe ser llevado a cabo dentro de unos parámetros de hábito de crecimiento, madurez, adaptación local, factores específicos de resistencia a plagas y enfermedades, tamaño de semilla y las diferentes preferencias en calidad de cada región, donde se consume fríjol. De no ser así, el material resultante tendrá un valor económico reducido; por tal razón, las estrategias de mejora deben ser guiadas al uso de materiales con potencial para aumentar el rendimiento, sin afectar estos factores importantes (Iriarte et al. 2006).

Durante la última década, se ha incrementado el interés en las formas silvestres de plantas cultivadas, en general, y de leguminosas, en particular. Éstas son utilizadas como una fuente importante de genes, principalmente, para resistencia a plagas y a enfermedades, ayudando a la producción de nuevas variedades de alto rendimiento (Gepts, 1991). Los silvestres representan una fuente de diversidad adicional para los cultivados, convirtiéndose en un reto para el mejorador encontrar el sistema de cruzamiento y de selección, que permita transferir esta diversidad con la mayor eficiencia a los cultivados, sobre todo, si se trata de caracteres poligénicos (Gepts, 1994), dada su menor heredabilidad y la importancia agronómica de los mismos, como en el caso del rendimiento.

El fitomejoramiento debería ser uno de los principales usuarios del germoplasma conservado en los bancos, como fuente del recurso "genes valiosos", a ser introducidos en la base genética adaptada. Pero la brecha genética entre el pool de germoplasma élite de los programas de mejoramiento genético y el de germoplasma ubicado en los bancos puede ser grande, resultando necesario realizar etapas de trabajo, previas al desarrollo de variedades para facilitar su utilización.

El pre-mejoramiento (pre-breeding) realiza este trabajo de intermediación, incorporando genes o grupos de genes asociados a características favorables, provenientes de genotipos exóticos, otras especies, géneros o familias vegetales. El material resultante, "genéticamente valorizado", es posteriormente incorporado en los programas de mejoramiento, como líneas parentales para el desarrollo de cultivares. Por esta razón, este proceso también se denomina "diseño de líneas parentales" (parent building). El pre-mejoramiento constituye, entonces, la primera etapa en la utilización de los recursos genéticos, luego de las etapas de colecta, de identificación, de conservación y de caracterización/evaluación (Pritsch, 2001; Paredes et al. 2010). 
Cuando se trabaja con cruzamientos entre genotipos silvestres y cultivados, la mayor parte de la variación observada puede ser explicada a partir de unos cuantos genes mayores, relacionados con el síndrome de la domesticación y los genes, con menores efectos, son imposibles de identificar (Tanksley \& Nelson, 1996). Se cree que al eliminar la variación atribuida a los genes de domesticación por medio de retrocruces, se revelarán aquellos alelos novedosos que puedan contribuir positivamente al rendimiento. Para hacer esto de manera eficiente es necesario introgresar el genoma del silvestre en bloques, por medio de la metodología de retrocruces avanzados, sugerida por Tanksley \& Nelson (1996), como una nueva estrategia de mejora genética basada en ciclos de retrocruzamiento sin selección, seguido de varios ciclos de autofecundación, "inbred backcross", propuesto por Bliss \& Brown (1983). Recientemente, el Centro Internacional de Agricultura Tropical -CIAT-, ha venido aplicando esta metodología para generar una población, partiendo de una variedad andina mejorada de tipo Radical y una accesión silvestre colombiana. Con los datos obtenidos de los ensayos buscan mostrar incrementos en el rendimiento de variedades andinas de fríjol común y confirmar la utilidad del proceso de retrocruces avanzados para introgresar genes de alto rendimiento, desde genotipos silvestres hacia cultivados (Iriarte et al. 2006; Blair et al. 2006).

En este trabajo, se evaluaron 95 líneas RC2 (de segundo retrocruce), más cinco testigos en las condiciones agroecológicas de la Granja Experimental Tunguavita en Paipa (Boyacá), con el objeto de seleccionar progenitores potenciales para futuros cruzamientos o líneas promisorias con adaptación a la zona, adecuado rendimiento y calidad de grano.

\section{MATERIALES Y MÉTODOS}

El experimento, se realizó en un lote de la Granja Experimental Tunguavita en Paipa (Boyacá), propiedad de la Universidad Pedagógica y Tecnológica de Colombia, ubicada a $2.470 \mathrm{msnm}$, con $13,8^{\circ} \mathrm{C}$ de temperatura promedio anual y $74 \%$ de humedad relativa, con un régimen bimodal de lluvias que aportan $835 \mathrm{~mm}$ de precipitación anual.

Material vegetal: La población RC2, de la cual provienen las 95 líneas, se desarrolló a partir del cruce entre el cultivar Radica Cerinza, como padre recurrente y la accesión silvestre G10022, de la Colección de Germoplasma del CIAT, como padre donante. El padre recurrente Radical Cerinza es, según Astudillo \& Blair (2008), un cultivar local arbustivo de grano mediano y color rojo, colectado en Restrepo (Valle). La semilla de los genotipos en evaluación fue facilitada por el CIAT, mediante un Acuerdo de Transferencia de Germoplasma (ATG).

Manejo agronómico: La siembra, se efectuó en surcos de
$3 m$ de longitud por cada material, a 0,6m de distancia entre surcos y $10 \mathrm{~cm}$ entre plantas. Con base en recomendaciones de Buenas Prácticas Agrícolas para el cultivo de fríjol (Arias et al. 2007), para la fertilización constante, como enmienda y fuente de calcio, se aplicó el equivalente a $768 \mathrm{~kg} \mathrm{ha}^{-1}$ de $\mathrm{CaO}$ con Abono Paz del Río (0-9-0-48). La dosis de fósforo, como $\mathrm{P}_{2} \mathrm{O}_{5}$ fue de $157 \mathrm{~kg} \mathrm{ha}^{-1}$ con fuentes Abono Paz del Río y el compuesto 17-6-18-2. Se aplicaron dosis de $\mathrm{N}$ y $\mathrm{K}_{2} \mathrm{O}$ equivalentes a $40 \mathrm{~kg} \mathrm{ha}^{-1}$, usando como fuente el compuesto 17-6-18-2. Se efectuó manejo preventivo de enfermedades, con aplicación de clorotalonil + benomil, en dosis de $25 \mathrm{~cm}^{3}$ $+20 \mathrm{~cm}^{3} / 20 \mathrm{~L}$ de mezcla, respectivamente, debido a que por el tipo de cruce original se puede presentar susceptibilidad a patógenos, en algunas líneas en evaluación. Para el manejo de plagas, se aplicó etofenprox, en dosis de $10 \mathrm{~cm}^{3} / 20 \mathrm{~L}$ de mezcla. Las arvenses se manejaron con control manual.

Diseño experimental: Se evaluaron 95 líneas y 5 genotipos testigos (el padre recurrente Radical Cerinza (2 veces), NUA 35, CAL 96 y AFR 298), en un diseño de látice 10 x 10, con tres repeticiones. Para el análisis estadístico de las variables evaluadas: rendimiento de grano seco al $14 \%$ de humedad (REND) y sus componentes: número de vainas por planta (VPP), número de granos por vaina (GPV) y peso de 100 granos (P100G), más los días a floración (DFL) y los días a maduración (DAM), se utilizó el sistema estadístico SAS v.8e (Cary, NC). Como primer paso, se comprobó estadísticamente el ajuste de las variables a los supuestos de normalidad y de homogeneidad de varianzas del modelo, mediante la prueba de normalidad, con el estadístico Shapiro - Wilk y la prueba de Levene, respectivamente, para aplicar estadística paramétrica. A las variables que no se ajustaron a la normalidad, se les aplicó transformación de los datos, siendo efectiva la transformación raíz cuadrada $(\sqrt{X})$, para algunas de ellas. Para las variables en las cuales ninguna transformación fue efectiva, se les realizó análisis de varianza de una vía no paramétrico, mediante la prueba de Kruskal - Wallis. En las variables con comportamiento ajustado a normalidad, se aplicó prueba de comparación de medias de Duncan; también se realizó análisis de correlación lineal múltiple. Para la determinación de humedad del grano y convertir los datos de rendimiento final de grano seco y P100G al 14\% de humedad de los materiales evaluados, se utilizó un Medidor Motomco Moisture Meter modelo 919 del Laboratorio de Semillas de FENALCE en Tunja.

\section{RESULTADOS Y DISCUSIÓN}

Para los genotipos evaluados, inicialmente, mediante prueba de normalidad, se observó que los datos de ninguna de las variables se ajustaban a la normal. Solamente a los datos de número de vainas por planta (NVAI) y rendimiento final de grano seco (REND), se les logró comportamiento ajustado a la normal, mediante la transformación raíz cuadrada $(\sqrt{X})$. 
En el análisis de varianza (Tabla 1), se puede observar que el diseño de látice fue más preciso que el diseño de bloques completos al azar, como lo demuestra el valor de su eficiencia relativa respecto al segundo, que fue de 113,29. En la tabla 2, se muestra parte de la prueba de comparación de medias de Duncan para NVAI y REND de 7 líneas seleccionadas, entre las 95 evaluadas, por su mayor rendimiento de grano y tipo de grano, con características cercanas (color rojo y tamaño) al del padre recurrente Radical Cerinza. Se observa que la línea BID 30 presentó el mayor rendimiento de grano, con $3.894 \mathrm{~kg} \mathrm{ha}^{-1}$, superior significativamente al de Radical Cerinza en $1.811 \mathrm{~kg} \mathrm{ha}^{-1} \mathrm{y}$ al de los demás testigos. Las otras 6 líneas seleccionadas mostraron también un buen comportamiento y tipo de grano, superando los $3.000 \mathrm{~kg} \mathrm{ha}^{-1}$ de rendimiento. Estas siete líneas se muestran promisorias para continuar su avance y selección con la metodología de retrocruces avanzados.

Tabla 1. Análisis de varianza para rendimiento y número de vainas/planta en genotipos evaluados. Granja Experimental Tunguavita. Paipa, Boyacá. 2010-A.

\begin{tabular}{|l|c|c|c|}
\hline \multirow{2}{*}{$\begin{array}{c}\text { Fuentes de } \\
\text { variación }\end{array}$} & \multicolumn{3}{c|}{ Cuadrados Medios } \\
\cline { 2 - 4 } & G.L & NVAI $^{\mathbf{1}}$ & $\begin{array}{c}\text { REND. } \\
\text { (kg/ha) }\end{array}$ \\
\hline Replicaciones & 2 & 3,0952 & 160,97 \\
\hline $\begin{array}{l}\text { Bloques dentro } \\
\text { de replicaciones (Aj.) }\end{array}$ & 27 & 1,474 & 227,12 \\
\hline Componente B & 27 & 1,474 & 227,12 \\
\hline Tratamientos (Sin Aj.) & 99 & 1,1288 & 204,49 \\
\hline Error intrabloque & 171 & 0,54 & 47,6247 \\
\hline Error de B. C. randomizados & 198 & 0,6749 & 72,1015 \\
\hline Total & 299 & 0,814 & 116,53 \\
\hline
\end{tabular}

${ }^{1}$ : Variables con transformación raíz cuadrada.

Eficiencia relativa frente a $\mathrm{DBCA}=113,29$

G.L.: Grados de libertad. NVAI: Numero de vainas/planta. REND; Rendimiento

Tabla 2. Medias ajustadas de siete líneas RC2 seleccionadas de las 95 evaluadas y comparadas con testigos para las variables NVAI y REND. Granja Experimental Tunguavita. Paipa, Boyacá. 2010-A.

\begin{tabular}{|l|l|l|}
\hline \multicolumn{1}{|c|}{ LÍNEA/GENOTIPO } & \multicolumn{1}{c|}{ NVAI } & \multicolumn{1}{c|}{ REND (kg/ha) } \\
\hline BID 30 & $31,62 \mathrm{ab}$ & $3893,61 \mathrm{a}$ \\
\hline BID 112 & $23,71 \mathrm{abcd}$ & $3719,94 \mathrm{a}$ \\
\hline BID 91 & $34,80 \mathrm{a}$ & $3510,50 \mathrm{a}$ \\
\hline BID 47 & $25,92 \mathrm{abc}$ & $3157,73 \mathrm{ab}$ \\
\hline BID 80 & $21,90 \mathrm{bcd}$ & $3075,87 \mathrm{ab}$ \\
\hline BID 65 & $22,99 \mathrm{abcd}$ & $3055,99 \mathrm{ab}$ \\
\hline BID 77 & $29,09 \mathrm{ab}$ & $3021,39 \mathrm{ab}$ \\
\hline Radical Cerinza & $14,68 \mathrm{de}$ & $2083,10 \mathrm{bc}$ \\
\hline NUA 35 & $15,28 \mathrm{cde}$ & $1652,82 \mathrm{c}$ \\
\hline AFR 298 & $15,50 \mathrm{cde}$ & $1516,82 \mathrm{c}$ \\
\hline CAL 96 & $10,66 \mathrm{e}$ & $1468,47 \mathrm{c}$ \\
\hline
\end{tabular}

DMS al 0,05 $=11,3761 \quad$ DMS al 0,05 $=1071,84$

Medias con letras distintas indican diferencia significativa según DMS al 0,05. 
Los excelentes resultados en incremento de rendimiento respecto al progenitor recurrente cultivado, demuestran segregación transgresiva positiva y confirman que las variedades silvestres tienen el potencial de aportar genes para alto rendimiento a las variedades cultivadas, constituyéndose en un valioso recurso germoplásmico para el mejoramiento genético del cultivo, como lo demostraron inicialmente en arroz, en China, donde comprobaron que QTL's derivados de $O$. rufipogon, una variedad silvestre de arroz, estuvieron asociados con incremento en el rendimiento, en una variedad hibrida (Xiao et al. 1996; Xiao et al. 1998) y como se ha deducido de investigaciones realizadas en arroz y en fríjol por el CIAT, en Colombia (Moncada et al. 2003; Iriarte et al. 2006). Estos resultados también coinciden con lo reportado por Herrera \& Acosta (2008), en cuanto a que en cruzamientos de genotipos silvestres con genotipos cultivados, se obtiene una ganancia genética, en cuanto a rendimiento.

El estudio de detección de QTL's, mediante marcadores moleculares en esta misma población de líneas con la metodología de retrocruces avanzados, lo está desarrollando el CIAT (datos sin publicar).

Barrios (2011) utilizó una retrocruza (RC2F2:5) entre Radical Cerinza y la accesión silvestre G24390 para, mediante marcadores microsatélites, construir un mapa genético e identificar posibles QTLs asociados a características agronómicas de interés, relacionadas con características agronómicas asociada a rendimiento. Se hallaron un total de 9 QTLs para las características fenotípicas evaluadas, por medio del análisis por intervalo compuesto, entre los que se resalta el QTL REND4,2, asociado a la característica rendimiento en la localidad de Popayán, que explicó una variabilidad fenotípica del $21 \%$, atribuida al padre silvestre G24390, demostrando también la importancia de la introgresión de características de importancia, desde accesiones silvestres a líneas élite de fríjol.
En cuanto al número de vainas por planta (NVAI), las líneas BID 91 y BID 30 presentaron los mejores resultados, con 35 y 32 vainas, respectivamente, coincidiendo con su alto rendimiento y mostrando diferencia significativa con Radical Cerinza y con los otros testigos, respecto a este componente (Tabla 2).

En la tabla 3, efectivamente se observa que el rendimiento final de grano seco de los genotipos evaluados presentó su mayor coeficiente de correlación $(r=0,6828)$ en forma positiva y altamente significativo, con el componente número de vainas por planta (NVAI). Este resultado es coincidente con numerosos reportes de investigación, a nivel nacional e internacional, respecto a que el número de vainas por planta es el principal componente del rendimiento en fríjol (Nienhuis \& Singh, 1986; Ranalli, 1996; Furtado et al. 2002; Gómez \& Frankow-Lindberg, 2005; López \& Ligarreto, 2006). El rendimiento también presentó correlación positiva y altamente significativa, aunque de menor magnitud, con el peso de 100 granos $(r=0,5027)$, lo cual, también ha sido reportado en algunos estudios en fríjol, aunque con resultados no siempre coincidentes en este sentido (Coimbra et al. 1999).

En la tabla 3, para analizar e interpretar la correlación del Vigor con las demás características evaluadas, es necesario tener en cuenta que la escala estándar que se utiliza para su evaluación, es inversa en sus valores numéricos, que expresan la calificación de cada genotipo, o sea, que las líneas más vigorosas que el testigo tienen calificación numérica baja, 1 o 3, al testigo se le asigna calificación 5 (vigor normal), mientras que en los vigores inferiores al testigo, es decir, los genotipos con menor vigor, su calificación numérica es alta, 7 o 9 (CIAT, 1987). En otras palabras, que un menor valor en la escala refleja un mejor comportamiento en cuanto a esta característica; es por esta razón, que la mayoría de los coeficientes de correlación del Vigor con las otras variables evaluadas fue de signo negativo, pero en realidad se deben interpretar como de signo positivo.

Tabla 3. Coeficientes de correlación de Pearson para características evaluadas en 100 genotipos de fríjol. Granja Experimental Tunguavita. Paipa, Boyacá.

\begin{tabular}{|c|c|c|c|c|}
\hline Característica & VIG & NVAI & NGRA & P100g \\
\hline NVAI & $-0,6795$ N.S. & & & \\
\hline NGRA & $-0,2298 * *$ & $-0,1420 *$ & & \\
\hline P100G & $-0,3546 * *$ & 0,0281 N.S. & $0,1504 * *$ & \\
\hline REND & $-0,3389 * *$ & $0,6828 * *$ & $0,3643 * *$ & $0,5027 *$ \\
\hline
\end{tabular}

VIG: Vigor; NVAI: Número de vainas/planta; NGRA: Número de granos/vaina; P100G: Peso de 100 granos en gramos; REND: Rendimiento.

(N.S): No significativo; (*): Significativo al 5\%; (**): Significativo al $1 \%$. 
Para los 100 genotipos evaluados, las variables: Vigor, definida por CIAT (1987), como la adaptación vegetativa, días a floración (DAF), días a maduración (DAM), número de granos por vaina (NGRA) y peso de 100 granos (P100G), que no presentaron comportamiento ajustado a la normalidad y, por cuanto, se les realizó análisis de varianza no paramétrico, se observa en la tabla 4 que, según la Prueba de Kruskal Wallis, no se presentaron diferencias significativas entre los genotipos en cuanto a DAF y DAM, lo cual, era de esperarse, debido a que estas líneas en la etapa anterior de evaluación fueron seleccionadas buscando un fenotipo más cercano a Radical Cerinza que al progenitor silvestre, voluble y de ciclo tardío. Para las variables: Vigor, NGRA y P100G, según la misma prueba (Tabla 4), sí se presentó diferencia significativa, lo cual indica que, al menos una de las medianas de los genotipos evaluados fue diferente para estas características.

Se podría concluir y recomendar que las siete líneas RC2 seleccionadas (Tabla 2), por su adaptación al área de evaluación en Paipa (Boyacá), significativo mayor rendimiento y adecuado tipo de grano, deben continuar avanzando, mediante la metodología de retrocruces avanzados hacia el padre recurrente Radical Cerinza, pues son promisorias para al final del proceso convertirse en potenciales progenitores, para ser involucrados en nuevos cruzamientos o en líneas promisorias para la futura obtención de nuevas variedades arbustivas de fríjol, para el Departamento de Boyacá. En el actual avance, algunas de estas líneas aún no poseen una arquitectura de planta adecuada, pues presentan tendencia a ser postradas y requerirían de retrocruces adicionales hacia el padre recurrente Radical Cerinza, para obtener hábitos de crecimiento recomendables.

Se vislumbra con este y otros trabajos similares, la utilidad de la metodología de retrocruces avanzados, como técnica de pre-mejoramiento para la introgresión de genes benéficos, desde materiales silvestres hacia cultivares mejorados.

El buen comportamiento de líneas de la población en el área de evaluación, se debe, sin duda, a la adaptación a la zona del progenitor recurrente Radical Cerinza, que ha sido el ge- notipo de mejor comportamiento en la Granja Tunguavita (Paipa, Boyacá), en anteriores ensayos realizados.

Conflictos de intereses: El manuscrito fue preparado y revisado con la participación de todos los autores, quienes declaramos que no existe ningún conflicto de intereses que ponga en riesgo la validez de los resultados presentados. Financiación: Este estudio fue financiado por la Dirección de Investigaciones (DIN) de la Universidad Pedagógica y Tecnológica de Colombia. UPTC, Tunja.

\section{BIBLIOGRAFÍA}

1. ADAMS, M. 1977. An estimation of homogeneity in crop plants with specific reference to genetic vulnerability in the dry bean, Phaseolus vulgaris L. Euphytica. 26:665-679.

2. ARIAS, J.H.; JARAMILLO, M.; RENGIFO, T. 2007. Manual Técnico: Buenas Prácticas Agrícolas (BPA) en la producción de fríjol voluble. CORPOICA - MANA - FAO. C.I. La Selva. Medellín.

3. ASTUDILLO, C.; BLAIR, M.W. 2008. Evaluación del contenido de hierro y zinc en semilla y su respuesta al nivel de fósforo en variedades de fríjol colombianas. Agr. Col. 26:471-476.

4. BARRIOS, R. del P. 2011. Identificación de QTLs asociados a características agronómicas de interés, en una retrocruza avanzada de frijol común (Phaseolus vulgaris L.). Disponible desde Internet en: http://ciatlibrary.ciat.cgiar.org/Articulos_Ciat/2011_Identificacion_de_QTLS_Frijol.pdf (con acceso el 25/07/12).

5. BLAIR, M.W.; IRIARTE, G.; BEEBE, S. 2006. QTL analysis of yield traits in an advanced backcross population derived from a cultivated Andean wild common bean (Phaseolus vulgaris L.) cross. Theoret. Appl. Genetics. 112:1149-1163

Tabla 4. Resultado del análisis de varianza no paramétrico para las variables no normales de genotipos evaluados, según la Prueba de Kruskal - Wallis.

\begin{tabular}{|l|r|r|r|r|c|}
\hline \multicolumn{1}{|c|}{$\begin{array}{c}\text { Prueba de } \\
\text { Kruskal - Wallis }\end{array}$} & \multicolumn{1}{c|}{ VIGOR } & DAF & DAM & NGRA & \multicolumn{1}{c|}{ P100G } \\
\hline Chi - Cuadrado & 131,72 & 108,74 & 106,78 & 168,75 & 256,06 \\
\hline G.L. & 98 & 98 & 98 & 98 & 98 \\
\hline Pr $>$ Chi - Cuadrado & $0,0131 *$ & 0,2153 N.S. & 0,2556 N.S. & $<0,0001 *$ & $<0,0001 *$ \\
\hline
\end{tabular}

G. L.: Grados de libertad. *: Diferencia significativa (5\%). N.S.: No significativo. 
6. BLISS, F.A.; BROWN, J.W.S. 1983. Breeding common bean for improved quantity and quality of seed protein. Janick, J. (Ed.). Plant Breeding Reviews 1: 59102.

7. CCI - MADR, 2009. Encuesta Nacional Agropecuaria. Disponible desde Internet en: www.agronet.gov.co/ www/docs_agronet/201046112648_RESULTADOS_ ENA_2009.pdf (con acceso el 10/1 $\overline{1} / 10$ ).

8. CIAT (CENTRO INTERNACIONAL DE AGRICULTURA TROPICAL). 1987. Sistema estándar para la evaluación de germoplasma de fríjol. van Schoonhoven, A.; Pastor-Corrales, M.A. (Comps.). Cali, Colombia. 56p.

9. CNPAF - EMBRAPA. 2003. Cultivo de feijoeiro. Disponible desde Internet en: http://sistemasdeproducao. cnptia.embrapa.br/FontesHTML/Feijao/CultivodoFeijoeiro/index.htm (con acceso el 03/04/10).

10. COIMBRA, J.L.M.; GUIDOLIN, A.F.; FÉLIX DE CARVALHO, F.I.; COIMBRA, S.M.M.; MARCHIORO, V.S. 1999. Análise de trilha I: Análise do rendimento de graos e seus componentes. Ciência Rural, Santa María 29(2):213-218.

11. FURTADO, M.R.; CRUZ. C.D.; CARDOSO, A.A.; FERNANDEZ COELHO, A.D.; PETERNELLI, L.A. 2002. Análise de trilha do rendimento do feijoeiro e seus componentes primários em monocultivo e em consórcio com a cultura do milho. Ciência Rural. 32(2):217-220.

12. GEPTS, P. 1991. La biotecnología aclara el proceso de domesticación del fríjol. Diversity. 7(1-2):52-53.

13. GEPTS, P. 1994. Análisis moleculares del proceso de domesticación en plantas: El ejemplo del fríjol común (Phaseolus vulgaris L.). En: Congreso Latinoamericano de Genética (Área Vegetal) y Congreso de Fitogenética. Monterrey (México). 25-30 Sep. 1994. Memorias. Chapingo, México. Sociedad Mexicana de Fitogenética. p.3-28.

14. GÓMEZ, O.J.; FRANKOW-LINDBERG, B.E. 2005. Yield formation in Nicaraguan landraces of common bean compared to bred cultivars. J. Agr. Sci. 143:369-375.

15. HERRERA, T.; ACOSTA, J. 2008. Rendimiento de tres tipos de cruzas entre genotipos silvestres y cultivados de frijol. Agr. Técn. Méx. 34(2):167-176.

16. IRIARTE, G.; BLAIR, M.W.; HOYOS, A.; BEEBE, S. 2006. Evaluación agronómica de una retrocruza avanzada entre una accesión silvestre colombiana y la variedad cultivada de fríjol común, ICA Cerinza. Fitotecn. Col. 6(1):24-32.

17. LÓPEZ, J.E.; LIGARRETO, G.A. 2006. Evaluación por rendimiento de 12 genotipos promisorios de fríjol voluble (Phaseolus vulgaris L.) tipo Bola Roja y Reventón para las zonas frías de Colombia. Agr. Col. 24(2):238-246.

18. McCLEAN, P.E.; MYERS, J.R.; HAMMOND, J.J. 1993. Coefficient of parentage and cluster analysis of North American dry bean cultivars. Crop Sci. 33:190-197.

19. MONCADA, M.; MARTÍNEZ, C.; McCOUCH, S. 2003. Detección de QTLs para rendimiento y caracteres de importancia económica en una población $\mathrm{F}_{2} \mathrm{RC}_{2}$ del cruzamiento Oryza sativa x Oryza rufipogon. Fitotecn. Col. 3(2):69-85.

20. NIENHUIS, J.; SINGH, S.P. 1986. Combining ability analyses and relationships among yield, yield components and architectural traits in dry bean. Crop Sci. 26:21-27.

21. PAREDES, M.; BECERRA, V.; CONDÓN, F.; GERMÁN, S.; BARBIERI, R.L. 2010. Utilización de los recursos fitogenéticos. En: Estrategia en los recursos fitogenéticos para los países del Cono Sur / IICA Montevideo: PROCISUR, IICA, 2010. p.97-116.

22. PRITSCH, C. 2001. El pre-mejoramiento y la utilización de los recursos fitogenéticos. En: Estrategia en recursos fitogenéticos para los países del Cono Sur. PROCISUR. 2001. Documentos. Montevideo, Uruguay. p.111-121.

23. RANALLI, P. 1996. Phenotypic recurrent selection in common bean (Phaseolus vulgaris L.) based on performance of S2 progenies. Euphyt. 87(2):127-132.

24. SINGH, S.P.; URREA, C.A.; GUTIÉRREZ, J.A.; GARCÍA, J. 1989. Selection for yield at two fertilizer levels in small-seeded common bean. Can. J. Plant Sci. 69:1011-1017.

25. TANKSLEY, S.D., NELSON, J.C. 1996. Advanced backcross QTL analysis: a method for the simultaneous discovery and transfer of valuable QTL from germoplasm into elite breeding lines. Theoret. Appl. Genetics. 92:191-203.

26. VOYSEST, O.; VALENCIA, M.C.; AMÉZQUITA, M.C. 1994. Genetic diversity among Latin America An- 
dean and Mesoamerican common bean cultivars. Crop Sci. 34:1100-1110.

27. VOYSEST, O. 2000. Mejoramiento Genético del fríjol (Phaseolus vulgaris L.): Legado de variedades de América Latina 1930-1999. Centro Internacional de Agricultura Tropical. CIAT. Cali (Colombia). 195p.

28. XIAO, J.; LI, J.; YUAN, L.; TANKSLEY, SD. 1996. Identification of QTLs affecting traits of agronomic importance in a recombinant inbred population derived from a subspecific rice cross. Theoret. Appl. Genetics. 92:230-244.

29. XIAO, J.; LI, J.; GRANDILLO, S.; SANG-NAG, A.; YUAN, L.; TANKSLEY, S.D.; McCOUCH, S.R. 1998. Identification of trait-improving quantitative trait loci alleles from a wild rice relative, Oryza rufipogon. Genetics. 150:899-909.

Recibido: Septiembre 23 de 2011

Aceptado: Abril 2 de 21013 